\title{
Ação cultural e teatro como pedagogia
}

\section{Resumo}

Beatriz A. V. Cabral UDESC Pq2/CNPq

A ação cultural no Teatro como Pedagogia é vista como aquela que busca quebrar a reprodução de comportamentos (habitus) através de sua configuração como experiência estética. Como tal, vai além do teatro como informação e entretenimento, e implica formas de conhecimento que dialogam com formas de identificação e subjetividade. Sob este ponto de vista, a relação entre ação cultural e texto é considerada pelo ângulo da ressonância e do reconhecimento estético, focalizando a materialidade do suporte (texto) associada à imaterialidade de sua carga informacional e emocional. A possibilidade de aproximar a ação cultural da ação social está, neste sentido, na aproximação entre as noções de diferença, desentendimento e partilha do sensível, assim como na distinção entre conflito e tensão, uma vez que o político estaria na estética e não no tema.

\section{Abstract}

The cultural action in theatre as pedagogy is seen here as one that seeks to break the reproductive behavior (habitus) through its configuration as aesthetic experience. As such, goes beyond the theatre as entertainment and information, and implies forms of knowledge that dialogue with forms of identification and subjectivity. The relationship between cultural action and text, from this point of view, is considered from the perspective of resonance and aesthetic recognition by focusing on the materiality of the support (text) associated with the immateriality of its informational and emotional burden. The possibility of associate cultural action and social action lies on the one hand, in the interaction between the notions of difference, disagreement and distribution of the sensible, and on the other hand in the distinction between conflict and tension, once the politics would be on the aesthetics and not on the theme.

A Ação Cultural, pelo âmbito do ensino, pode ser vista como a ação do professor que busca quebrar a reprodução de comportamentos (habitus) que impedem a ampliação do olhar e da percepção do aluno. Este entendimento refuta o ensino-instrução, o qual supõe que todos alcançam o conhecimento da mesma forma e podem ser avaliados da mesma maneira; exige o questionamento do que se ensina e da maneira pela qual se ensina. A questão central passa a ser: que aspectos e que dimensões teatrais podem ampliar a significação da ação do professor? É neste sentido que o Teatro como Pedagogia está centrado em sua dimensão artística e é a partir dela que se vincula à estética, à ética e à política, tornando-se uma forma de combater padrões de comportamento que reproduzem o senso comum. $O$ pressuposto aqui é que se $o$ fazer artístico for significativo, e tiver ressonância com os interesses e preocupações 
dos participantes, causará impacto e provavelmente mudanças de percepção; caso contrário, será um desserviço à causa a que se propõe.

\section{Habitus Versus Mudança}

Escola, família e mídia são agentes interdependentes na socialização das crianças - em algumas ocasiões elas estão associadas, em outras se confrontam. Quando associadas, mantém a tradição; quando em confronto, promovem rupturas. Como pensar a ação cultural a partir desta perspectiva de uma interação dinâmica entre família, escola e mídia?

De acordo com Pierre Bourdieu, a noção de habitus permite entender o relacionamento entre estas instituições de condicionamento social e as subjetividades individuais - isto, se partirmos do entendimento que habitus não significa destino, e sim um condicionamento cultural que leva o indivíduo a agir ou optar por algo.

O conceito de habitus, tal como investigado por Bourdieu, aponta para algumas questões que permitem repensar a ação cultural do professor:

- Habitus é um sistema de formas adquiridas de percepção, pensamento e atitudes, que delimitam ou governam nossas interações no campo social.

- O habitus é insinuado (introduzido ou criado) no indivíduo através da violência simbólica (não explicitamente), isto é, através de discursos e ações de reprodução social e cultural.

Portanto, o habitus é um sistema de disposições pessoais, estruturadas socialmente, as quais têm uma função estruturante em nossa mente, e dirigem nossas ações e atitudes cotidianas. Como tal, limita ou influencia as oportunidades que nos aparecem. Entretanto, a mudança é possível - Bourdieu considera a mobilidade do habitus como decorrente de experiências individuais ou coletivas.

Aqui serão focalizados aspectos teóricos sobre como a ação cultural, através da experiência do fazer teatral, torna-se um campo privilegiado para mudanças das formas de percepção e ações cotidianas.

\section{Teatro como Pedagogia, como Cultura, como Ruptura}

A perspectiva das pedagogias crítica e pós-crítica subsidia a perspectiva da mudança de hábitos no campo do fazer teatral, pois questiona a forma de perceber questões éticas e epistemológicas de seu ensino. 
De acordo com Henri Giroux (1957), a pedagogia crítica passa a se associar à reflexão sobre os princípios que regem a ação pedagógica e não à implementação de uma determinada metodologia (o "como" fazer). Neste sentido, ação cultural (a proposição de um fazer) e ação pedagógica (sua condução) não se medem pela expectativa de resultados específicos, mas se constituem como processos de investigação, cujo produto o professor não prevê e nem controla (apesar da possibilidade de confrontá-lo através de problematizações e desafios).

Seguindo este ponto de vista, a expressão teatro como pedagogia é introduzida aqui para indicar uma possível ruptura com delimitações e limitações impostas a priori no campo da pedagogia do teatro. Entre estas, a identificação de estilos e formas de fazeres como excludentes entre si, a dissociação do teatro na educação da arte teatral, a exacerbação do social e do educativo em detrimento do cultural (o que implica a exclusão de complexidades), a indistinção entre acesso à cultura ${ }^{1}$ e acesso aos bens culturais.

A ação cultural do teatro poderá, potencialmente, incidir sobre ou gerar uma ação social, com variações de intensidade ao nível da criação e da recepção, desde que não haja expectativas de resultado. Em teatro, e na arte em geral, a mobilidade da interpretação, ao nível da produção e da recepção, e quando abre espaço para a expressão individual e particular de cada participante, introduz a diferença e a distinção como critério de avaliação.

Jacques Rancière considera que a conexão entre política e estética está na singularidade do indivíduo artista. Para o filósofo, o teatro, a escrita, as artes plásticas, são formas artísticas que constituem "práticas da palavra e do corpo" - são, portanto, formas de partilha do sensível que operam um deslocamento necessário à reflexão e à transformação social. Segundo o autor, trata-se da incerta realidade da arte, na qual o argumento em si legitima o desentendimento e os atos estéticos configuram a experiência, pois estes levam a novos modos do sentir e novas formas de subjetividade política. Assim, a liberdade expressiva se associa à ampliação de configurações sensíveis. A ambiguidade e a recusa de formalização de uma "mensagem objetiva" na expressão artística imprime mobilidade de sentidos, o que impulsiona novas interpretações e permite a criação de mundos.

Se a ação cultural parte do princípio de que a cultura (e o teatro) como pedagogia atinge o emocional e o racional, é possível afirmar que o engajamento contínuo

\footnotetext{
1 "Acesso à cultura" é uma expressão inadequada, em qualquer circunstância em que seja mencionada, pois todo
} ser humana tem sua cultura, seja ela ou não condizente com os costumes e moral da sociedade em que vive. 
do indivíduo com atividades culturais e artísticas contribui para a quebra e mudança de habitus. Assim, a qualidade e a continuidade de um trabalho artístico significativo para o indivíduo podem mudar sua visão de mundo e perspectivas, pois quanto maior sua significação cultural, mais significativo seu potencial social.

Tomaz Tadeu da Silva (2005) ao defender a pedagogia como cultura e a cultura como pedagogia, afirma que os processos pedagógicos são comparáveis aos processos de sistemas culturais, na medida em que ambos transmitem uma variedade de formas de conhecimento vitais à formação da identidade e da subjetividade. "Do ponto de vista pedagógico e cultural", afirma o autor, "não se trata simplesmente de informação ou entretenimento: trata-se em ambos os casos, de formas de conhecimento que influenciarão e comportamento das pessoas de maneiras cruciais e até vitais" (2005, p.140).

Historicamente, lembra Tomaz Tadeu, os processos pedagógicos e culturais diferem principalmente pelos recursos econômicos e tecnológicos que mobilizam, os quais facilitam aos processos culturais formas sedutoras e irresistíveis de apresentação. Os processos culturais apelam para a emoção e a fantasia, para o sonho e a imaginação, mobilizando uma economia afetiva, que hoje não pode mais ser ignorada pelo campo da pedagogia.

O teatro como pedagogia e como cultura implica o conhecimento de si e do outro, mobilizando esta economia afetiva, e eventualmente fazendo a diferença. $A$ carência de recursos econômicos e tecnológicos não significa apenas o desconhecimento de formas sedutoras e irresistíveis de apresentação, poisrefere principalmente às condições de trabalho e formação continuada do professor. Enquanto um programa cultural mobiliza recursos financeiros, equipe e tempo de trabalho, um professor em geral atua de forma isolada, em múltiplas turmas com mais de 30 alunos cada. Qual contribuição o teatro, entendido como pedagogia e como cultura, poderá trazer a este professor?

\section{Momentos - quando a ausência ou a presença da ação cultural indica a diferença}

Um breve testemunho da observação de duas situações, a primeira com adolescentes e role-play games pela internet, a segunda com drama e crianças em sala de aula, explicitam como o significado da ação cultural pode fazer a diferença no cotidiano das atividades de lazer e de ensino. 


\section{Testemunho 1}

Anos atrás observei um grupo de adolescentes jogando Ultima VII, um role playing game de computador (CD). Me espantou o número de horas que passavam, por dia, concentrados e engajados no jogo. A partir daí me questionei como nós, professores de teatro, com espaço, som, interações no momento, muitas vezes temos dificuldade em conseguir 50 minutos de engajamento, ao vivo. À época foi lançado Ultima Online, um dos primeiros jogos online com múltiplos jogadores. Os adolescentes se inscreveram imediatamente (era necessário pagar uma taxa mensal), e passaram a jogar em horários incomuns a fim de interagir com maior número de pessoas de hemisférios distintos. Após dois ou três meses de entusiasmo com a mudança, os encontrei de volta ao "Ultima VII" ...

Eu: Não pagaram a mensalidade?

Eles: Pagamos.

Eu: A internet está fora do ar?

Eles: Não. Tá OK.

Eu: Por que vocês não estão online?

Eles: Se não há um grande jogador online, só aparece contribuição estúpida, nenhuma história interessante, nem boas falas.

\section{Testemunho 2}

Entre 1990 e 1993 tive a oportunidade de acompanhar o trabalho de drama education ${ }^{2}$ conduzido por Dorothy Heathcote em escolas, com turmas de crianças ou adolescentes, e na universidade com grupos de mestrandos. Aqui relato um episódio do processo "Mary Morgan".3

Heathcote conduzia processo de drama através de episódios nos quais desempenhava papeis que provocassem a ação dos participantes (individualmente ou em

\footnotetext{
${ }^{2}$ As expressões drama in education, process drama e drama são usadas por autores distintos e muitas vezes pelo mesmo autor. Drama in Education predomina no campo do teatro na escola; Process Drama,em trabalhos centrados em um texto como pré-texto, comum em contextos variados; Drama, usado mais recentemente, é comum em contextos nos quais a atividade já está instaurada ou quando o professor fala ou escreve para seus pares (conferências e congressos neste campo de conhecimento).

${ }^{3}$ Dorothy Heathcote Archive 1990-1993 at Manchester Metropolitan Univesity. Organizado e mantido por Sandra Hesten. Os arquivos de trabalhos anteriores e posteriores de Dorothy Heathcote podem ser acessados em www. did.stu.mmu.ac.uk/dha
} 
grupo), mudando de postura ou papel para expandir ou modificar o entendimento das ações e o sentido de teatralidade.

Durante o processo Mary Morgan, Heathcote criou um episódio centrado em um cemitério, onde cada criança (8 anos de idade) colocou um túmulo (criado na aula de artes visuais) para uma pessoa imaginária que morrera em meados do século XIX, época em que a causa da morte estava geralmente incluída na epígrafe de sua lápide. O cemitério de Presteigne (País de Gales), onde a história real aconteceu, inclui duas lápides para Mary Morgan, uma singularidade que indica uma situação rica de eventos dramáticos ${ }^{4}$.

Heathcote iniciou este episódio pedindo que cada criança ficasse em pé ao lado do túmulo que havia criado (de papelão), como se fosse uma árvore. Ela então caminhou por entre os túmulos, identificando cada imagem corporal como uma espécie diferente de árvore, descrevendo a forma de sua raiz, galhos e folhas. Sua descrição, na grande maioria dos casos, alterou e realçou a expressão física do aluno. Na sequência, ela começou a questionar cada árvore, a fim de criar a atmosfera do cemitério e ao mesmo tempo ouvir algo sobre a opinião da comunidade local sobre os mortos ou a morte ${ }^{5}$.

A primeira pergunta foi dirigida a uma criança com reputação de ser "difícil" (a professora havia antecipado esta informação).

Heathcote: Aqui está, há mais de 300 anos, um poderoso e forte carvalho. Por favor, diga-me carvalho, o que você observou durante estes anos?

Carvalho: Não muito! (respondendo de cara amarrada)

Heathcote: Que triste! (Ela seguiu para a próxima 'árvore'). Que salgueiro protetor debruçado sobre este pequeno túmulo! (Ela lê a inscrição na lápide). Você certamente observou muitas pessoas cuidando deste túmulo durante muitos anos.

Salgueiro: Não muito!

Heathcote seguiu questionando as árvores e incluindo referências às suas epígrafes, e abrindo oportunidades para respostas. Ainda assim,

todos responderam no estilo de "não muito". Ao terminar o roteiro, disse:

\footnotetext{
${ }^{4}$ Jennifer Green, "The Morning of Her Day". Green, jornalista de passagem pela vila de Presteigne, no País de Gales, ao visitar o cemitério e encontrar as duas lápides, pesquisou o arquivo público da localidade. A história de Mary Morgan (17 anos de idade), auxiliar doméstica no castelo local, é narrada a partir dos autos do processo que a condenou à morte por enforcamento, após esconder sua gravidez enfaixando o abdômen, e matar a criança ao nascer. Foi a última morte por enforcamento em Gales, em 1805.

${ }^{5} \mathrm{O}$ tema da morte é indicado no currículo inglês, e, portanto, focalizado de alguma forma, em cada escola.
} 
Que triste encontrar um cemitério, ao redor de uma bela igreja, no centro de uma pequena cidade, onde os mortos foram esquecidos. Suas histórias morreram com eles. Poderíamos dizer que este é um lugar sem memória? Poderiam vocês, crianças dos tempos modernos, trabalhar como detetives para solucionar este mistério?

Os dois testemunhos mostram como a mobilização de recursos econômicos e tecnológicos, em si, pode não fazer a diferença.

No primeiro caso, a versão online e os recursos tecnológicos recém-introduzidos no mercado, com a possibilidade de interagir com participantes de outras partes do mundo, foi excitante e motivadora. Entretanto, retornaram ao CD. Ao conversar com o grupo para entender melhor o retorno, eles me explicaram que quando algum professor de literatura ou história está online e coordena o encontro, sugerindo e organizando ações coletivas ou confrontos, o jogo vale a pena. Caso contrário, os participantes ficam caminhando aleatoriamente, acumulando pontos e matando quem encontram pelo caminho. No CD, disseram, são oferecidas as opções de ação e alternativas de fala para cada ação. Estas alternativas saíram de obras de Shakespeare, Alan Poe, Swift, Oscar Wilde etc. As alternativas de texto tornam qualquer opção interessante.

O segundo caso aponta para o teatro como pedagogia no cotidiano de uma sala de aula comum, com cadeiras afastadas e sem qualquer outro recurso além da relação professor-alunos. A professora associa história, real e ficcional, à expressão física e presença de atores-espectadores. Ela introduz os nomes de 30 espécies de árvores, dramática e teatralmente em contexto, alimentando e redefinindo possibilidades de expressão e construção da narrativa. E, mais importante, exemplifica o potencial de levar em consideração as reações mais negativas dos alunos e transformá-las em material para criar uma atmosfera que acentue as fronteiras entre os contextos real e ficcional.

\section{Nas fronteiras entre o real e o ficcional}

A ação cultural, quer através da montagem de um texto clássico, de sua apropriação e atualização, ou de uma criação coletiva a partir de investigação histórica ou temática, requer refazer o mapeamento de parâmetros de lugar, identidade, história e poder. As fronteiras entre o real e o ficcional são ativadas e provocam mudanças de percepção e expectativas. Estas em geral resultam da variedade (alternativas) e qualidade de referências linguísticas e contextuais cruzadas nos encontros teatrais, e estão associadas à transgressão ou à ressonância com o contexto real dos participantes. 
De acordo com Henri Giroux (1997, p. 30), a possibilidade de quebrar barreiras em termos de conhecimento e acesso a informações tem a ver com o papel do professor como intelectual, como aquele que desafia os limites do estabelecido.

Estes limites são observados e desafiados em situações nas quais as fronteiras entre o real e ficcional são transitadas através da imersão dos participantes; através do prazer de entrar no espaço da ficção, que segundo Janet Murray, refere-se ao prazer de navegar, de encontrar o novo, o diferente:

\begin{abstract}
"Uma narrativa excitante, em qualquer meio, pode ser experimentada como uma realidade virtual porque nossos cérebros estão programados para sintonizar nas histórias com uma intensidade que pode obliterar o mundo à nossa volta (...) A narrativa é também uma experiência liminar (...) As histórias evocam nossos desejos e medos mais profundos porque fazem parte da mágica região de fronteira (...) nós precisamos manter o mundo virtual "real" fazendo com que ele permaneça "fora dali". (Murray, 2003, pp.101-103).
\end{abstract}

O professor de drama/teatro usa procedimentos que cruzam tempo, espaço e presença para mediar a interação dos alunos e favorecer o desenvolvimento do processo de significação. Trata-se de um processo contínuo de estruturação da narrativa cênica.

Entretanto, o procedimento para promover imersão na criação coletiva ainda requer uma dimensão estética de significação e reconhecimento. Para tanto, é necessário planejar momentos significativos ao longo do processo.

Retornando a Janet Murray e sua análise do conceito de imersão, "trabalhar na fronteira entre os mundos real e ficcional é a essência do processo do drama, e da própria performance" (ibidem, p.105). Para David Davis, "a fronteira aponta para a imprecisão da forma artística; para o movimento e deslocamento do conteúdo cada vez que o observador o leia novamente - aqui reside a evidência de um bom trabalho de arte" (Davis, 1992p. 3).

O ponto importante a ser enfatizado é que o mundo virtual traz liberdade para experimentação e expressão; seu potencial analógico traz ressonância com o mundo real e, portanto, reconhecimento estético.

\title{
Ressonância e Reconhecimento Estético
}

O drama e o teatro contemporâneos, sejam quais forem suas origens e inserções, buscam formas de comunicação com contextos e espaços distintos como uma maneira de expandir sua ressonância com questões familiares aos participantes e promover reconhecimento estético. $\mathrm{O}$ desafio torna-se equilibrar momentos de ruptura e de continuidade. 
Neste sentido, o texto - quer em sua forma original, quer como fragmentos que se aproximam tematicamente, como sequência de imagens ou como associação de objetos, apresenta um papel central. O texto aponta, sugere ou questiona aspectos da identificação cultural, provoca estranhamento ao identificar ou diferenciar julgamentos de práticas sociais, reflete uma sensibilidade pré-existente e como tal cria ou desperta tal sensibilidade, amplia e expande repertório artístico e percepção estética.

A ação cultural de selecionar um texto, programar sua introdução e formas de interação com os participantes inclui considerar sua materialidade como suporte, associada à imaterialidade de sua carga informacional e emocional. Selecionar o material a ser introduzido a partir de seu potencial informacional, emocional, ético e expressivo corresponde ao que Barthes acentuou em distintos momentos como aquele capaz de produzir pregnant moments (momentos prenhes de significação). São estes momentos que afastam o risco de considerar a ação cultural apenas como ação social, como "um serviço" a ser avaliado de acordo com a expectativa de um resultado pré-estabelecido.

\section{A ação cultural como configuração da experiência estética}

Segundo Rancière, "os atos estéticos como configurações da experiência criam novos modos de percepção sensorial e induzem novas formas de subjetividade" (2004, p. 9). Nesta perspectiva, são considerados, ao se falar em educação e arte, o sensorial e o subjetivo da ação criativa, seu suporte material e imaterial, o real e as fronteiras da realidade.

Assim, se a ação cultural em si pode ser vista como ação social, o contrário dificilmente ocorre. A ação social parte de objetivos e recursos específicos que precisam ser avaliados de acordo com a aferição de resultados também específicos: as mudanças ocorridas em formas de vida e ações sociais. A ação cultural, avaliada a partir de análise da recepção, inclui motivações e manifestações críticas como contradições, diferenças e desentendimentos. Sua observação e análise permitem detectar mudanças de percepção, usualmente através das ações expressivas do aluno/ator; ações estas em constante movimento e modificações.

Neste sentido, uma forma de aproximar ação cultural e social poderia ser a aproximação entre as noções de desentendimento e partilha do sensível, segundo Rancière, e a de filosofia da diferença, de Deleuze. 
Para Rancière, a estética e a política são maneiras de organizar o sensível: de dar a entender, de dar a ver, de construir a visibilidade e a inteligibilidade dos acontecimentos . Quando caminham juntas abrem possibilidades com base no encontro discordante de percepções individuais. Política e estética, segundo o filósofo, têm assim em comum a delimitação do visível e do invisível, do audível e inaudível, do pensado e do impensável, do possível e do impossível. A distribuição do sensível é o sistema de fatos (autoevidentes) da percepção dos sentidos que simultaneamente revela/expõe a existência de algo em comum e a delimitação que define as partes e posições respectivas dentro dele. A distribuição do sensível, portanto, estabelece algo que é compartilhado e exclusivo às partes envolvidas e a maneira dos indivíduos terem uma parte nesta distribuição. Aquilo que é exclusivo de cada indivíduo gera possíveis desentendimentos, cuja negociação e discussão abrem novas perspectivas e possibilidades.

Para Deleuze, e observando a questão por outro ângulo, o teatro, devido à sua constituição crítica, opera modificando elementos do texto original. Assim, a fonte modificada deixa de ser representada, e o fazer teatral se torna o da não-representação - o ponto de vista do apropriador. Este agenciamento da enunciação, decorrente principalmente da articulação do individual com o político, está centrado usualmente nos componentes linguísticos e sonoros - a língua, a fala e o gesto como variações contínuas. Assim, se uma mesma situação ou texto é apropriado por diferentes grupos, as variações linguísticas e gestuais conduzem a significações distintas, e configuram um teatro da não-representação.

Outro aspecto assinalado por Deleuze, que repercute no campo da pedagogia, é que o teatro permanece representativo cada vez que toma os conflitos como objeto, uma vez que estes já estão normatizados, codificados e institucionalizados. Buscar soluções possíveis, segundo Deleuze, não significa escapar da representação, um movimento da repetição; a repetição, em outro contexto e circunstância, substitui a representação pela apresentação (2009, p.31). Na área específica do drama o conflito como objeto é o ponto de partida; a mobilidade da significação requer a distinção entre conflito e tensão.

\section{A ação cultural em teatro e a distinção entre conflito e tensão}

Ao escolher um texto, tema ou imagem para um processo de criação em teatro, o professor usualmente não busca sua repetição ou identidade, mas sim um ponto 
de vista ou perspectiva, e formas de questioná-106. Ao enquadrar situações e lançar frases do texto para estabelecer diálogos ou confrontos, ele está oferecendo formas de ampliar a percepção do tema e integrá-lo às próprias preocupações e interesses dos alunos. Neste sentido, a condução do processo se caracteriza como uma ação cultural que equilibra momentos de identificação e estranhamento, nos quais a diferença ganha contornos que serão produtivos, caso seja trabalhada através de momentos de tensão que explicitem e ao mesmo tempo evitem possíveis conflitos.

Segundo Gavin Bolton (1984), enquanto a estrutura denota a relação entre os componentes da cena, a tensão indica a nossa experiência dessa estrutura. Nos jogos teatrais e no drama o relacionamento estrutural que implica tensão está geralmente explícito: a indefinição entre recompensa e punição, a necessidade de tomar uma decisão que envolva risco, a espera, as barreiras, os enigmas, os dilemas. A experiência dramática é bem sucedida, afirma Bolton, quando o grupo intuitivamente reconhece que a intensidade de uma situação reside na dificuldade de tomar uma decisão que poderá lhe ser favorável ou não. A tensão antecede o conflito e, em drama, sobrepõe-se a ele, dado o seu caráter de experiência existencial, que prioriza a dinâmica interna da uma situação em detrimento de uma possível sequência de ações (esta centrada na representação).

A crença que conflito deva ser a principal fonte de tensão em drama/teatro, ou qualquer gênero, segundo Bolton, é um equívoco. Isto porque desperta prontamente emoções que tendem a sobrepujar o pensamento e não permitem acessar recursos de distanciamento mais sutis. Tal fenômeno é particularmente observado na esfera do trabalho em grupo, na qual a raiva se une com o sentimento de grupo para criar o que é conhecido como "efeito yahoo": um crescendo de indisciplina e barulho sob a direção e proteção do conflito dramático, que invariavelmente destrói o drama. O conflito, uma vez despertado, é difícil de controlar, e pode facilmente espalhar limites não claros entre o comportamento apropriado a um personagem e aquele apropriado a um participante. Já a tensão, ao ativar a energia através do confronto entre expectativas e limitações,

\footnotetext{
${ }^{6}$ Isto não significa que, dependendo da experiência e interesse do professor e dos alunos, não se possa jogar com as possíveis significações de um texto decorado previamente. O professor dinamarquês Dan Olsen apresentou, em uma conferência na Inglaterra, uma experiência realizada com o texto infantil "O Patinho Feio" montado por um grupo de seus estudantes e gravado em vídeo. Esta gravação foi apresentada para grupos de diversos países, solicitados a repetir as ações observadas e o texto traduzido, podendo retornar ao vídeo quantas vezes achassem necessário. A observação de várias montagens, representando as mesmas situações e ações, revela claras diferenças e identificações culturais.
} 
implica afastar três riscos que impedem a interação ética - estética - política: o de considerar a comunidade ou o grupo como uma entidade consensual com fronteiras fixas; o de afastar a ambiguidade e considerar suas necessidades como prontamente identificáveis; o de acreditar que seus objetivos possam ser alcançados de forma isolada e independente dos interesses da cultura dominante.

Embora questões em torno de consenso, certeza, verdade, objetividade e realidade estejam bastante exploradas e questionadas na área de ciências humanas, inclusive em teatro, elas ainda pontuam, aqui e ali no processo coletivo do drama. Uma das razões poderia estar na criação de uma identidade grupal como objetivo e concepção de trabalho, pois a identidade de grupo tende a anular as diferenças e a atenuar as desigualdades, e acaba por nivelar as especificidades individuais. Consenso torna-se a condição sine qua non de sua eficácia. Consenso torna-se também uma ferramenta eficaz no estabelecimento de habitus.

\section{Ação Cultural e Teatro como Pedagogia: texto, traduções e fronteiras}

Repetir um texto, argumenta Roberto Machado (2009), não é buscar sua identidade, mas afirmar sua diferença; é pensar em seu próprio nome usando o nome de um outro, organizar seu texto a partir de um ponto de vista, de uma perspectiva que faz o objeto estudado sofrer pequenas ou grandes torções, a fim de ser integrado às suas próprias questões. Para Deleuze, o teatro é crítico quando opera amputando, subtraindo alguma coisa, alguns dos elementos do texto original, para fazer aparecer algo diferente. Não é apenas a matéria do texto, a história original que é modificada; é também a forma de apresenta-la, que cessa de ser representação, constituindo-se como um teatro da não-representação. A interação sensorial com o espaço, o texto e o outro vai definir a energia em cena. Por esta perspectiva é possível perceber a identidade como diferença.

Em que medida a associação entre texto e ação cultural permite mediar esta interação sensorial com o espaço e o outro? Se no processo de criação a "tensão" do contexto da ficção gera a energia para a investigação cênica, as torções e amputações (o jogar com a linguagem) permitem o distanciamento para perceber a relevância do material investigado e as formas pessoais de responder aos problemas e à tensão gerada. Está aberto o espaço para a ambiguidade, a indefinição, a incerteza. Isto porque, segundo Rancière, as palavras têm um poder de ruptura: elas embaralham a evidência segundo a qual as coisas seriam simplesmente o que elas são. Segundo o 
autor, o mesmo acontece com a arte, pois o regime estético da arte realiza suas possibilidades essenciais ultrapassando a si mesmo, criando formas de vida.

Helen Nicholson, em editorial sobre "Atos de Tradução"7 ressalta que a linguagem tanto limita quanto amplia horizontes, e que "novas formas de ver, ouvir e pensar poderão ser encontradas através da expressão performática de questões sociais" (2010, p. 307). Neste editorial Nicholson remete a uma palestra de Jacques Derrida (Oxford Amnesty Lecture, 1982), na qual o filósofo chama a atenção para o relacionamento entre linguagem, subjetividade e direitos humanos, e considera que estes são sempre construídos pela linguagem e carregam as marcas de sua cultura e histórias. Para Derrida, é necessário respeitar a cultura do outro para afirmar a própria - isto não é apenas político, é também poético. Nicholson parte desta reflexão de Derrida para apresentar um número temático de $\mathrm{RiDE}^{8}$ sobre performances e experiências interculturais. Atos de tradução, enfatiza Nicholson, movem ideias teóricas à pratica através de eventos performativos.

É neste sentido que uma ação cultural, no teatro como pedagogia, que tenha como ponto de partida e se alimente de um texto literário (dramático ou não), contribui para a ampliação da linguagem e da percepção estética, mantendo a atuação ou experiência na fronteira entre o real e o ficcional. Seguindo o famoso dictum de Wittgenstein, "os limites de minha linguagem são os limites de meu mundo", associo-o à afirmação de Rancière, para quem “o político está na estética, não é temático". O texto, contextualizado, confrontado (traduzido), e transformado se afasta da explanação e entra no campo da exploração, permitindo que a ação cultural pretendida se configure como um processo de aproximação descontínua e não-linear do tema, uma constante mudança de perspectivas que a aproxima da experiência estética.

\section{Bibliografia}

BARTHES, R. The Pleasure of the Text. New York: Hill and Wand, 2975.

BOLTON, G. Drama as Education. London: Longman, 1984.

BOURDIEU, P. A Distinção. Crítica social do julgamento. São Paulo: EdUSP,2007. O poder simbólico. Rio de Janeiro/Lisboa: Bertrand Brasil/Difel, 1989.

CABRAL, B. "A Estética do Dissenso em Processos Coletivos". Ensaios em Cena. Org. Cássia Navas, Marta Isaacsson, Silvia Fernandes. São Paulo: ABRACE/CNPq, 2010.

\footnotetext{
7 Helen Nicholson, "Acts of Translation", Research in Drama Education. Vol. 15, No 3, pp. 305-307. Londres: Routledge, 2010.

${ }^{8}$ RiDE - Research in Drama Education. London, Routlege. http://www.informaworld.com, Vol 15, No 3, 2010.
} 
"Manifestos - política e arte em performance". URDIMENTO -Revista de Estudos em Artes Cênicas. Vol. 1, N. 17, set.2011.

. "Presença e Processos de Subjetivação". Revista Brasileira de Estudos da Presença. UFRGS: Vol.1, pp. 107-120, 2011.

DAVIS, D. O Óbvio e o Obtuso. Rio de janeiro: Nova Fronteira, 1990.

DERRIDA, J. A Escritura e a Diferença. São Paulo: Perspectiva, 2009.

DELEUZE, G. Diferença e repetição. São Paulo: Edições Graal, 2009

GREEN, Jennifer. The Morning of Her Day.London: Darf Publishers, 1990.

GIROUX, H. Os Professores como Intelectuais - rumo ma pedagogia crítica da aprendizagem. Porto Alegre: Artes Médicas, 1997.

Cruzando as Fronteiras do Discurso Educacional. Porto Alegre: ARTMED.1999.

MACHADO, R. Deleuze, a arte e a filosofia. Rio de Janeiro, Zahar, 2009.

MURRAY, J. Hamlet on the Holodek - The Future of Narrative in Cyberspace. New York: The Free Press, 1997.

NICHOLSON, H. "Atos de Tradução". RiDE: The Journal of Applied Theatre and Performance. London: Routledge: Vol. 15, No 3, August 2010, pp. 305-307.

RANCIÈRE, J. The Politics of Aesthetic. Londres: Continuum, 2004

"A Associação entre Arte e Política" Entrevista a Gabriela Longman e Diego Viana.

Revista Cult, 139, 2010.

SILVA, T. Documentos de Identidade - uma introdução às teorias do currículo. Belo Horizonte: Autêntica,2005.

WOLFE, K. "From Aesthetics to Politics: Rancière, Kant and Deleuze", Contemporary Aesthetics. Vol. 4, 2006. http://quod.lib.umich.edu/c/ca 